\title{
Research on Military Simulation System based on Multi-Agent
}

\author{
TAN Kai-jia \\ Military Logistics and Military \\ Technology Equipment Department \\ National Defence University \\ Beijing 100091, China
}

\author{
PEI Shuai \\ Military Logistics and Military \\ Technology Equipment Department \\ National Defence University \\ Beijing 100091, China \\ 2005peishuai@163.com
}

\author{
Qi Yong-qiang \\ Military Logistics and Military \\ Technology Equipment Department \\ National Defence University \\ Beijing 100091, China
}

\begin{abstract}
In this paper, the concept and characters of Agent technology are researched. By applying Agent technology into Military Simulation System, a Military Simulation System framework based on Multi-Agent technology is put forward. Each Agent, model warehouse, knowledge warehouse and database of the Military Simulation System framework are researched. Finally, the communication and cooperation between Agents are discussed.
\end{abstract}

Keywords-Multi-Agent; Military Simulation System; Simulation; Cooperation

\section{INTRODUCTION}

Agent technology comes from artificial intelligence and is an important concept in computer science field. Agent has abundant connotation and many definitions are put forward from society capacity, knowledge disposal and personification by people. Applying Agent technology to Military Simulation field is a hotspot aspect by now. In Military Simulation system development the means of concept modeling and system description based on Agent incarnate an original system development mode. It can describe complicated and uncertain problems in Military Simulation system and neatly describe military action between campaign entities in Military Simulation system by freedom and commutative characteristic. Applying this means can improve the intelligent level and circumstance suit capability of Military Simulation system.

\section{THE MiLITARY SimULATION SYSTEM FRAMEWORK BASED ON MULTI-AGENT}

It is the key design step of Military Simulation System that setting up concept model for Military entity action. Concept model can be described by using self-governed tools such as expression and chart to abstract simulation description from realistic campaign action. Agent technology is a good selfgoverned tool to describe Concept model. Concept characters of Military entity action can be researched and the in-house entity parts of Military Simulation System can be described as some function Agents by Agent technology. The Military Simulation System framework based on Multi-Agent can be designed by some function Agents which can describe military action between campaign entities. By this approach the realistic campaign simulation level for Military Simulation System can be improved.

\section{A. The Collectivity framework of system}

By describing the basic function of Military Simulation System, the collectivity framework of Military Simulation System can be separated into Agent floor and resource floor. Agent floor includes man-machine communion Agent, information catching Agent, information transmission Agent, command control Agent and exactness strike Agent. Resource floor includes database, model warehouse and knowledge warehouse. Database can offer system data for every Agent. Model warehouse can offer models for every Agent. Knowledge warehouse can offer rules and fact for every Agent. The collectivity framework of system is shown as Figure.1.

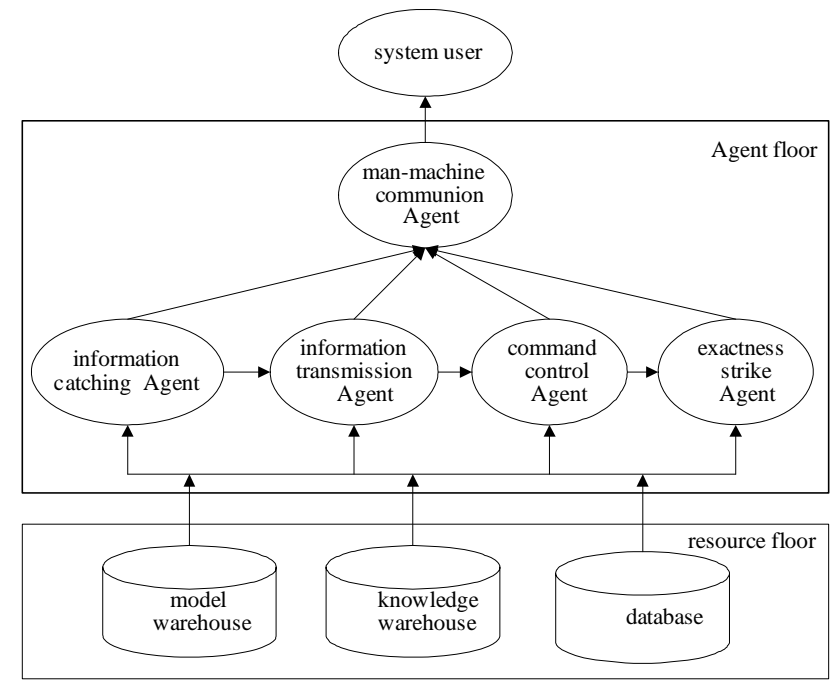

Figure 1. The Collectivity framework of Military Simulation System based on Multi-Agent

\section{B. Design of Agents}

1) Design of man-machine communion Agent

Man-machine communion Agent is the bridge between system user and military simulation system. It can adjust communication of rest Agents and communicate with system 
user. It is the capability of man-machine communion Agent that can learn user habits and accumulate user knowledge. A friendly and intelligent user interface can be afforded by manmachine communion Agent.

\section{2) Design of information catching Agent}

Military entity campaign action information can be gained by information catching Agent. The capability design of information catching Agent includes information catching extension design and capability parameter design. Information catching Agent is the catching window for Military entity campaign action information and emphasizes capability of information catching. It can estimate the pressure of information and distribute the information to information transmission Agent. It can gain more war field information but has weak defend capability. So campaign system can exert optimal efficiency by the availability between Agents.

\section{3) Design of information transmission Agent}

Military entity campaign action information can be transmitted by information transmission Agent. The capability design of information transmission Agent includes information transmission extension design and capability parameter design. Information transmission Agent can realize transmission between each Agents and accomplish cooperation between the military campaign entities. It can offer military campaign information form information catching Agent to command control Agent. The direction of transmission link reflects the information flow in military campaign simulation process.

\section{4) Design of command control Agent}

Command control Agent can accept information form information transmission Agent and make optimal campaign decision-making based on campaign effect to exactness strike Agent. By the analysis of campaign information and campaign mission, Command control Agent can uses knowledge consequence to choose decision-making rule based on rules in knowledge warehouse and give command to exactness strike Agent.

\section{5) Design of exactness strike Agent}

The capability parameter design of exactness strike Agent includes design of strike precision and strike extension. In campaign simulation process, exactness strike Agent can get information from information transmission Agent and accept command from command control Agent. Then exactness strike Agent can choose action plan and strike aims forwardly based on action rules and strike rules by command drive mechanism.

\section{Design of resource floor}

\section{1) Design of model warehouse}

In military simulation system diversified military entities model are stored by definite frame in model warehouse and offer accessorial decision-making to each agents. In model warehouse the storage methods include three methods. Firstly, model can be stored by data. Model is decomposed into model cell which can be described by data frame. Secondly, model can be stored by sentence. Model is decomposed into model cell which can be described by modeling sentence. Then, model can be stored by program. Model is decomposed into model cell which can be described by program function.

\section{2) Design of knowledge warehouse}

Knowledge warehouse is the warehouse of rules and truths for each Agent. The design of knowledge warehouse includes knowledge expressing and knowledge getting two processes. The process of knowledge expressing can describe the rules and truths by acceptable data frame for computer in promissory sign. The process of knowledge getting can get rules and truths for knowledge warehouse by handmade getting and system summarizing.

\section{3) Design of data}

The design of system data can be realized by Microsoft SQL Server2005 which is the streamlined DBMS. It can store system data into logic equipment by storeroom document form. It has manifold safety mechanism and dependability mechanism.

\section{COMMUNICATIONS AND COLLABORATION BETWEEN} AGENTS

\section{A. Communications mode between Agents}

Communications between Agents are the base for Agents Collaboration in military simulation system. New the regular Communications language is Knowledge Query and Manipulate Language. The Communications means of Agents system include blackboard system and message dialog system. In the military simulation system blackboard system can be used for communications between Agents. Man-machine communion Agent harmonizes else Agents communications. Blackboard system offer a share information work space in which each Agent can see blackboard system, exchange information and accept assignment. The blackboard system work flow is shown as Figure.2.

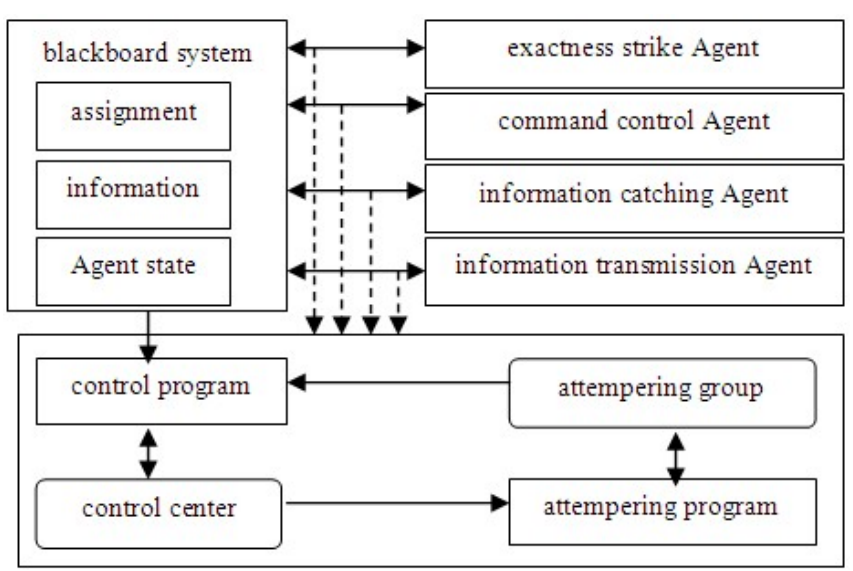

Figure 2. The blackboard system work flow

\section{B. Collaboration between Agents}

Collaboration between Agents can be realized by communication action with Agents. Each Agent has an information explaining implement and can translate accepted information into inner language of Agent. Then Agents synchronization and collaboration are simulated by Agent communication mechanism and agreement based on inner language of Agent. By collaboration between Agents the 
capability of information disposing and problem resolving in military simulation system can be greatly improved.

\section{CONCLUSION}

It is a useful attempting that using Multi-Agent technology into military simulation system development. The integrated and intelligent characteristic of military simulation system can be improved by Multi-Agent system frame. The research can offer some useful means for development of military simulation system despite some technology and development problems need more research.

\section{REFERENCES}

[1] LI Ying, BI Yi-ming, LIU Shun-cheng. An Agent-oriented Approach for Conceptual Model. Command Control and Simulation. 2009, 31(4):1517

[2] CHEN Qi-feng, DAI Jin-hai. Agent Synthesis of Operational Effectiveness of Space System of Systems. Journal of System Simulation. 2011,23(11):2352-2355.

[3] WANG San-xi, ZHU Jun-hui, LIU Feng,SHEN Shou-lin. Research on Agent-based Modeling and Simulation of Military Counter System. Fire Control and Command Control. 2009, 34(8):19-21.

[4] LI Yuan-zuo,YANG Xiao-duan,YIN Xiang-min. Collaboration Model of Army Weapons Multi-Agent Operation and Equipments Based on Simulation. Ordnance Industry Automation. 2009, 28(7):1-4.

[5] O. Shehory, A. Sturn. Evaluation of modeling techniques for agentbased system. Proc. of International Conference on Autonomous Agents, Montreal, 2001:624-631 